\title{
Differentiation of Contiguous Hydroxyl Groups by Regioselective Conversion of Acetonides into tert-Butyl Hydroxyalkyl Ethers
}

\author{
Wen-Lung Cheng, Sue-Min Yeh, ${ }^{1}$ and Tien-Yau Luh* \\ Department of Chemistry, National Taiwan University, Taipei, Taiwan 106, Republic of China
}

Received June 7, $1993^{\circ}$

Summary: Treatment of the acetonides of simple contiguous diols or those derived from carbohydrates with the Grignard reagent yields regioselectively the corresponding hydroxyalkyl ether.

Selective transformation of an acetal of a contiguous diol into the corresponding hydroxyalkyl ether would be highly useful in synthesis because the two hydroxyl groups can thus be differentiated. $\mathrm{TiCl}_{4}$ is commonly used to promote various kinds of cross-coupling reactions of acetals, ${ }^{2}$ and the reaction occasionally proceeds with high stereoselectivity. ${ }^{3}$ Regioselective modification of two vicinal hydroxy groups of glycerol via 1,2-O-benzylidene derivatives by reductive cleavage using DIBALH has been reported. ${ }^{4}$ Trimethylaluminum has also been employed to serve this purpose, and high selectivity was achieved only when the substrate contained a neighboring hydroxyl group for chelation. ${ }^{5}$ Although the reaction of a Grignard reagent with an acetal has been known for almost three decades, ${ }^{6}$ not much synthetic use has been reported. ${ }^{7}$ The protection of vicinal hydroxy groups of carbohydrates by acetal groups is widely used. Selective deprotection of these acetals would be particularly valuable in derivatization of carbohydrates. Described herein are the results which demonstrate a useful regioselective ring-opening reaction of acetonides with Grignard reagents.

In the beginning of this investigation, we tested the generality of this reaction by treating acetonides 1 with 4 equiv of Grignard reagents in refluxing benzene-ether $(5: 1)$ for $18 \mathrm{~h}$. After the usual workup procedure, the corresponding hydroxyalkyl ethers 2 were obtained in good yields (eq 1). ${ }^{4}$ Both five- and six-membered acetonides

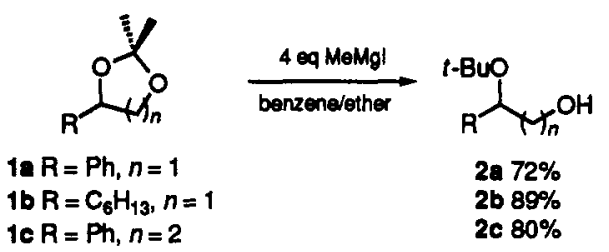

behaved similarly, and the $\mathrm{C}-\mathrm{O}$ bond of the less hindered site in 1 was cleaved regioselectively. Presumably, the oxygen atom on this site would coordinate to magnesium

- Abstract published in Advance ACS Abstracts, September 1, 1993. (1) Recipient of the Ministry of Education acholarship, 1992-93.

(2) For a review, see: Mukaiyama, T.; Murakami, M. Synthesis 1987, 1043.

(3) (a) Bartlett, P. A.; Johnson, W. S.; Elliott, J. D. J. Am. Chem. Soc. 1983, 105, 2088. (b) Mori, A.; Fujiwara, J.; Maruoka, K.; Yamamoto, $H$. Tetrahedron Lett. 1983, 24, 4581 .

(4) (a) Takano, S.; Kurotaki, A.; Sekiguchi, Y.; Satoh, S.; Hirama, M.; Ogasawara, K. Synthesis 1986, 811. (b) Takano, S.; Akiyama, M.; Ogasawara, K. Chem. Pharm. Bull. 1984, 32, 791. (c) Takano, S.; Akiyama, M.; Sato, S.; Ogasawara, K. Chem. Lett. 1983, 1593.

(5) Takano, S.; Ohkawa, T.; Ogasawara, K. Tetrahedron Lets. 1988 , $29,1823$.

(6) (a) Blomberg, C.; Vreugdenhil, A. D.; Homsma, T. Rec. Trav. Chim. 1963, 82, 355. (b) Mallory, R. A.; Rovinski, S.; Scheer, I. Proc. Chem. Soc. London 1964, 416 preferentially, resulting in the regioselective protection of the more hindered hydroxy group of a diol.

The presence of a neighboring oxygen moiety changed the selectivity. Thus, the reaction of 3 with $\mathrm{MeMgI}$ afforded the corresponding diol 4 in $78 \%$ yield (eq 2). It seemed likely that the chelation with magnesium leading to intermediate 5 may play a key role in controlling such selectivity.

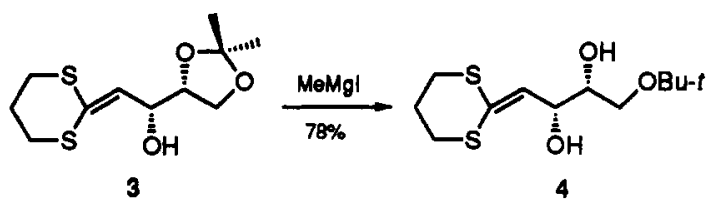<smiles>[X][M]O[C@H](C=C1SCCCS1)[C@@H]1COC(C)(C)O1</smiles><smiles>CCCCOC1C(OC)OC(CCCC)C(OC(C)(C)C)C1OC</smiles>

The extension of this reaction to sugar derivatives has been executed. Bisacetonides 6 were allowed to react with an excess amount of the Grignard reagent in benzeneether at $60^{\circ} \mathrm{C}$ for $4 \mathrm{~h}$ to give 7 exclusively (eq 3 ). The
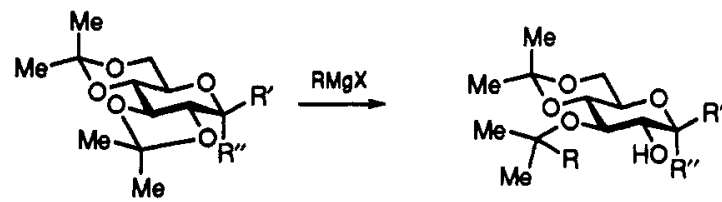

6a $R^{\prime}=H, R^{\prime \prime}=O M \theta$

$6 b R^{\prime}=O M e, R^{\prime \prime}=H$

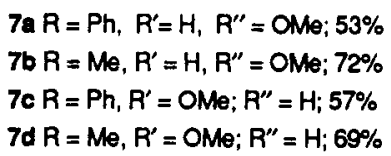

structures of 7 were unambiguously proven by 2D-COSY experiments. Interestingly, both anomeric $\alpha$ - and $\beta$-methoxy groups gave the same cleavage pattern, liberating the 2-hydroxyl derivatives 7. Again, the chelation of the $\mathrm{OMe}$ group and the neighboring oxygen function at $\mathrm{C}-2$ with magnesium may explain the results. When $6 a$ was treated with MeMgI under refluxing toluene conditions for $36 \mathrm{~h}$, diol 8 was isolated in $71 \%$ yield. In a similar manner, bisacetonides $9 a$ and $b$ were transformed, under similar conditions at $60^{\circ} \mathrm{C}$ overnight, into $10 \mathrm{a}$ and $\mathrm{b}$ in 79 and $75 \%$ yields, respectively (eq 4 ). On the other hand, diols

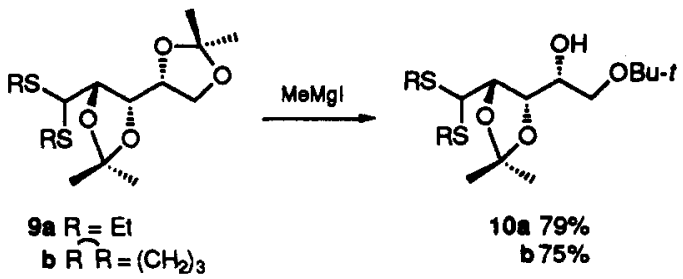


12 and 14 were obtained in 64 and $65 \%$ yields from the exhaustive reactions of $\mathrm{MeMgI}$ with 11 and 13 in refluxing benzene, respectively (eqs 5 and 6). It is worth noting that starting 11 was recovered in $96 \%$ yield upon treatment with $\mathrm{Me}_{3} \mathrm{Al} .{ }^{8}$

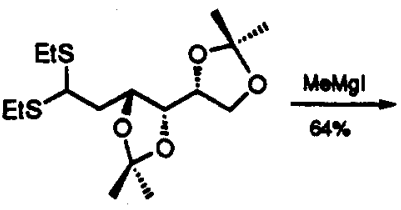

11

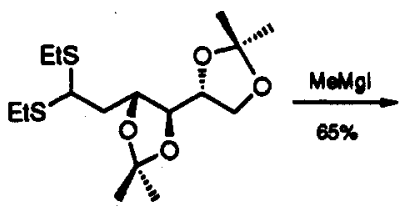

13

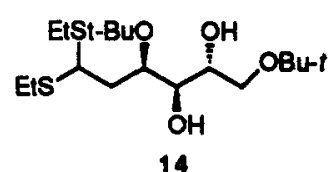

14

We recently demonstrated that the aliphatic dithioacetal group can undergo nickel-catalyzed cross-coupling reaction by means of chelation. ${ }^{\circ}$ Accordingly, the presence of an oxygen function which is in close proximity with the

(7) For a review, see: Trofimov, B. A.; Korostova, S. E. Rusa. Chem. Rev. 1975, 44, 41.

(8) Cf. rof 5 .

(9) (a) Wong, K.-T.; Luh, T.-Y.J. Am. Chem. Soc. 1992, 114, 7308. (b) Shiu, L.-L.; Yu, C. C.; Wong, K.-T.; Chen, B.-L.; Cheng, W.-L.; Yuan, T.-M.; Luh, T.-Y. Organometallice 1993, 12, 1018. (c) For a review on the coupling reactions of dithioacetals, seo: Luh, T.-Y. Acc. Chem. Res. $1991,24,257$. dithioacetal moiety would promote the corresponding coupling reaction of the sulfur moiety in the presence of the nickel catalyst. Indeed, the reaction of 11 with MeMgI in the presence of a catalytic amount of $\mathrm{NiCl}_{2}$ (dppe) gave 15 in $55 \%$ yield (eq 7). This result illustrates an interesting<smiles>C=CC[C@H](O[C@H](C)C(C)(C)C)[C@@H](O)[C@@H](O)COCC</smiles>

one-pot transformation of acetonides-dithioacetals into the corresponding hydroxy alkenes.

In summary, we have demonstrated a useful procedure to partially deprotect acetonides of vicinal diols to give the corresponding tert-butyl hydroxyalkyl ethers. The application of this reaction could be particularly useful in selective protecting-deprotecting of hydroxyl groups in carbohydrates. Further synthetic applications are in progress in our laboratory.

Acknowledgment. Support from the National Science Council of the Republic of China is gratefully acknowledged.

Supplementary Material Available: Experimental procedures for the preparation of $2 a-c, 4,7 a-d, 8,10 a, b, 12,14$, and 15 (6 pages). This material is contained in libraries on microfiche, immediately follows this article in the microfilm version of the journal, and can be ordered from the ACS; see any current masthead page for ordering information. 